\title{
Coeficientes de digestibilidade aparente de ingredientes para juvenis de jundiá
}

\author{
Paulo Roberto Campagnoli de Oliveira Filho ${ }^{1}$, Débora Machado Fracalossi ${ }^{1}$
}

\begin{abstract}
${ }^{1}$ Laboratório de Biologia e Cultivo de Peixes de Água Doce (LAPAD), Departamento de Aqüicultura, Centro de Ciências Agrárias (CCA), Universidade Federal de Santa Catarina (UFSC). Rod. Admar Gonzaga, 1346, CEP 88034-001, Florianópolis, SC, Brasil.
\end{abstract}

RESUMO - Foram determinados os coeficientes de digestibilidade aparente da MS, proteína e energia de cinco ingredientes (farelo de soja, glúten de milho, farinha de resíduo de peixe, quirera de arroz e milho) para juvenis de jundiá, Rhamdia quelen $(78,5 \pm 9 \mathrm{~g})$. A digestibilidade foi estimada pelo método indireto, utilizando-se óxido de crômio na concentração de $0,5 \%$ da dieta como indicador, efetuando-se a coleta de fezes a cada 4 horas por sedimentação. Entre os ingredientes testados, os maiores coeficientes de digestibilidade foram obtidos para o glúten de milho $(95,0 \%$ para proteína, $88,0 \%$ para energia e $82,2 \%$ para MS) e os menores para o milho (73,0\% para proteína, 59,1\% para energia e 57,2\% para MS). Os demais ingredientes apresentaram valores intermediários de digestibilidade. Obtiveram-se, para o ingrediente energético quirera de arroz, valores de $80,7 \%$ para proteína, $64,8 \%$ para energia e 60,5\% para a MS, enquanto, para os ingredientes protéicos farelo de soja e farinha de resíduo de peixe, os coeficientes de digestibilidade foram, respectivamente, de 88,6 e $77,7 \%$ para a proteína, 76,5 e $74,8 \%$ para a energia e 73,3 e $58,6 \%$ para a MS. Os resultados deste estudo demonstram que juvenis de jundiá, apesar do hábito alimentar onívoro, têm grande capacidade de digerir ingredientes protéicos e relativa dificuldade de digerir ingredientes energéticos, sugerindo que este peixe é onívoro com tendência à carnivoria.

Palavras-chave: digestibilidade, ingredientes, Rhamdia quelen

\section{Apparent digestibility coefficients of feed ingredients for jundia juveniles}

\begin{abstract}
The apparent digestibility coefficients of DM, protein and energy of five ingredients (soybean meal, corn gluten meal, fish meal, broken rice and ground corn) were determined for jundia juveniles $(78.5 \pm 9 \mathrm{~g})$. The indirect method was adopted for nutrient digestibility estimate. Chromium oxide $(0.5 \%)$ was added to the diet as marker, and feces were collected by sedimentation every four hours. Among all tested ingredients, corn gluten meal showed the highest apparent digestibility coefficients $(95.0 \%$ of protein, $88.0 \%$ of energy and $82.2 \%$ of DM), while ground corn showed the lowest apparent digestibility coefficients $(73.0 \%$ of protein, $59.1 \%$ of energy and $57.2 \%$ of DM). The other ingredients showed intermediary results. The broken rice (high energy ingredient) showed $80.7 \%$ of protein, $64.8 \%$ of energy and $60.5 \%$ of DM, while the soybean meal and fish processing waste meal (high protein ingredient) showed 88.6 and $77.7 \%$, respectively, for protein digestibility. The energy digestibility for the same ingredients were 76.5 and $74.8 \%$, while for DM were 73.3 and $58.6 \%$. The results show that jundia juveniles, although presenting an omnivorous feeding habit, is able to digest high protein ingredients better than high energy ingredients, suggesting that this species is an omnivore with carnivorous tendency.
\end{abstract}

Key Words: digestibility, ingredients, Rhamdia quelen

\section{Introdução}

No Brasil, entre as diversas espécies nativas com potencial para a piscicultura continental, encontra-se o jundiá, Rhamdia quelen. É um bagre nativo da América Latina (Silfvergrip, 1996) que tem apresentado bom desempenho em viveiros de piscicultura, principalmente no Sul do país, pelo crescimento satisfatório mesmo durante o inverno (Carneiro et al., 2002; Fracalossi et al., 2004).

Além disso, é de excelente aceitação pelo mercado consumidor, tanto para a pesca esportiva como para peixe de mesa. Os peixes adultos são onívoros, com preferência por detritos orgânicos, restos vegetais, peixes, crustáceos e insetos (Guedes, 1980; Meurer \& Zaniboni Filho, 1997). O crescimento dos alevinos em viveiros é rápido, pois atingem $5 \mathrm{~cm}$ de comprimento em menos de 30 dias (Gomes et al., 2000). Além do conhecimento da biologia alimentar do jundiá, estudos sobre sua nutrição são essenciais para o desenvolvimento do cultivo desta espécie.

Em estudo para determinação das exigências protéica e energética para alevinos, Meyer \& Fracalossi (2004) testaram diferentes concentrações de PB em dois níveis energéticos utilizando dietas semipurificadas. Os melhores resultados de ganho de peso e eficiência alimentar foram 
observados nas concentrações de 38 e $34 \%$ de PB para dietas contendo $3.000 \mathrm{kcal} / \mathrm{kg}$ e $3.500 \mathrm{kcal} / \mathrm{kg}$ de EM, respectivamente. Utilizando ingredientes práticos, Melo et al. (2002) avaliaram o desenvolvimento e a composição corporal de alevinos de jundiá alimentados com dietas contendo diferentes fontes de lipídeos. O desempenho e o rendimento de carcaça não foram afetados pelas diferentes fontes de lipídeos testadas (óleo de canola, óleo de fígado de bacalhau e banha suína). No entanto, esses autores observaram maior deposição de proteína na carcaça dos peixes quando forneceram a dieta contendo óleo de canola, enquanto a maior deposição de gordura visceral ocorreu com aquela contendo banha suína. Coldebella \& Radunz Neto (2002) também compararam três diferentes fontes protéicas (levedura de cana, farelo de soja e farinha de carne e ossos) na alimentação de alevinos de jundiá e demonstraram que a farinha de carne e ossos foi o ingrediente que propiciou o menor crescimento e ganho de peso, ao passo que a combinação farelo de soja e levedura de cana, quando incluídos na mesma proporção $(36,4 \%)$, foi a que proporcionou os melhores resultados. Embora existam estudos sobre nutrição com ingredientes práticos, ainda não há informações sobre a digestibilidade de ingredientes utilizados na formulação de rações para o jundiá.

A digestibilidade é um dos critérios adotados em estudos para avaliação da qualidade nutricional dos alimentos e da eficiência de dietas completas para animais, por meio da quantificação da fração do nutriente ou da energia absorvida do alimento que não é excretada nas fezes (Choubert et al., 1979; NRC, 1993; De Silva \& Anderson, 1998). Em peixes, como há dificuldade na coleta total das fezes e na medição precisa da quantidade de alimento consumido, utiliza-se o método indireto de medição de digestibilidade, que consiste na coleta parcial das fezes, por meio da utilização de um marcador indigestível na dieta. O marcador mais utilizado em estudos de digestibilidade em peixes é o óxido de crômio (Austreng, 1978; Bremer Neto et al., 2003).
A escolha de ingredientes com maior digestibilidade possibilita melhoria nos índices zootécnicos e diminuição na poluição da água dos viveiros de cultivo. Desse modo, realizou-se este estudo para determinar os coeficientes de digestibilidade aparente da MS, PB e EB do farelo de soja, do glúten de milho, da farinha de resíduo de peixe, da quirera de arroz e do milho para juvenis de jundiá.

\section{Material e Métodos}

O experimento foi conduzido em laboratório durante os meses de maio a outubro de 2004 utilizando-se 144 jundiás $(78,5 \pm 9 \mathrm{~g})$ provenientes de uma fazenda comercial. Os peixes foram aclimatados às condições experimentais por dez dias em seis tanques de alimentação com volume útil de 1,30 L, na densidade de oito peixes/tanque. Em cada tanque, os peixes foram alojados dentro de gaiolas com volume útil de $98 \mathrm{~L}$, costuradas com rede de fio de náilon de $1 \mathrm{~cm}$ entre nós para facilitar o manejo e reduzir o estresse dos peixes. A alimentação foi oferecida três vezes ao dia (às $11,14 \mathrm{e} 17 \mathrm{~h}$ ) até a saciedade aparente. Às $18 \mathrm{~h}$, os peixes eram transferidos para tanques apropriados para coleta de fezes (tanques de fibra de vidro cilíndrico-cônicos com volume útil de $200 \mathrm{~L}$ ), onde as fezes eram coletadas a cada 4 horas (às 22, 2, 6 e 10h), por sedimentação, em frascos de $250 \mathrm{~mL}$ acoplados ao fundo dos tanques. Os frascos ficavam imersos em isopor com gelo, a fim de minimizar os possíveis efeitos de degradação das fezes por ação bacteriana. Após cada coleta, as fezes eram transferidas para tubos de $50 \mathrm{~mL}$, centrifugadas a rotação de $2.296 \mathrm{gx}$ 2 min, secas em estufa a $50^{\circ} \mathrm{C}$ por 10 horas e congeladas a $-20^{\circ} \mathrm{C}$. O fotoperíodo do laboratório foi mantido em 14 horas de luz e a taxa de renovação de água dos tanques foi de aproximadamente $1,5 \mathrm{~L} / \mathrm{min}$

Os ingredientes utilizados nas rações foram moídos até atingirem $0,5 \mathrm{~mm}$ e misturados em um misturador automático em "Y". Aqueles incluídos em maior porcentagem

Tabela 1 - Composição dos ingredientes testados em ensaio de digestibilidade com juvenis de jundiá (\% da MS)

Table 1 - Proximate composition of feed ingredients tested in the digestibility trial with jundia juveniles (\%DM)

\begin{tabular}{|c|c|c|c|c|c|}
\hline \multirow[t]{2}{*}{$\begin{array}{l}\text { Composição }(\%) \\
\text { Composition (\%) }\end{array}$} & \multicolumn{5}{|c|}{$\begin{array}{l}\text { Ingrediente } \\
\text { Ingredient }\end{array}$} \\
\hline & $\begin{array}{l}\text { Milho } \\
\text { Ground corn }\end{array}$ & $\begin{array}{c}\text { Quirera de arroz } \\
\text { Broken rice }\end{array}$ & $\begin{array}{l}\text { Farinha resíduo peixe }{ }^{1} \\
\text { Fish processing waste meal }\end{array}$ & $\begin{array}{l}\text { Farelo de soja } \\
\text { Soybean meal }\end{array}$ & $\begin{array}{l}\text { Glúten milho } \\
\text { Corn gluten meal }\end{array}$ \\
\hline $\mathrm{MS}(D M)$ & 88,91 & 86,87 & 90,07 & 88,3 & 589,5 \\
\hline $\mathrm{PB}(C P)$ & 9,56 & 11,42 & 60,56 & 54,00 & 70,96 \\
\hline $\mathrm{EE}$ & 3,92 & 1,99 & 10,56 & 2,07 & 5,01 \\
\hline CIN (Ash) & 1,15 & 1,30 & 25,20 & 6,80 & 1,52 \\
\hline $\mathrm{FB}(C F)$ & 2,28 & 3,57 & - & 8,60 & 2,57 \\
\hline $\mathrm{EB}(G E)(\mathrm{kcal} / \mathrm{kg})$ & 3.886 & 3.786 & $\overline{4.030}$ & 4.174 & 5.321 \\
\hline
\end{tabular}

\footnotetext{
1 Fabricada a partir de resíduo de filetagem.
}

1 Fish processing waste. 
foram adicionados primeiramente, seguidos dos de menor porcentagem (mistura mineral e vitamínica e óxido de crômio). Para a mistura do óxido de crômio, foi realizada uma pré-mistura desse componente com os demais ingredientes, transferindo-os sucessivamente para frascos de maior tamanho $(250,400$ e $1.000 \mathrm{~mL})$. À medida que o óxido de crômio foi passado de um frasco para outro, adicionou-se uma quantidade de mistura de mais ingredientes. A concentração do óxido de crômio adicionado às dietas foi de $0,5 \%$. Após mistura, foram adicionados à massa os óleos de soja e peixe e depois a água (40\%). As rações foram peletizadas $\left(4 \mathrm{~mm}\right.$ de diâmetro), secas em estufa $\left(50^{\circ} \mathrm{C}\right)$ por 6 horas, resfriadas em temperatura ambiente, acondicionadas em sacos plásticos e armazenadas a $-20^{\circ} \mathrm{C}$. A composição dos ingredientes cuja digestibilidade foi determinada encontra-se na Tabela 1. A dieta basal, formulada para atender às exigências protéicas e energéticas do jundiá (Meyer \& Fracalossi, 2004), foi elaborada de forma a conter no mínimo $34 \%$ de PB e $3.650 \mathrm{kcal} / \mathrm{kg}$ de EM estimada (Tabela 2). A exigência dos demais nutrientes foi calculada com base nas exigências do bagre do canal, Ictalurus punctatus (NRC, 1993). As cinco dietas expe- rimentais foram compostas de $29,62 \%$ dos diferentes ingredientes-teste e de 70,38\% da dieta basal (Tabela 2).

Todas as análises das dietas e fezes foram realizadas conforme a metodologia descrita pela Association of Official Analitycal Chemists (AOAC, 1999), com exceção da análise de óxido de crômio, feita de acordo com a metodologia descrita por Bremer Neto et al. (2003). As dietas-teste foram submetidas às análises dos teores de MS (secagem a $105^{\circ} \mathrm{C}$ ), CIN (queima a $550^{\circ} \mathrm{C}$ ), PB (Kjeldahl, $\mathrm{Nx} 6,25), \mathrm{EE}$ (Soxleth após hidrólise ácida), FB, EB (bomba calorimétrica adiabática) e óxido de crômio (método colorimétrico). As fezes foram analisadas quanto aos teores de PB, EB e óxido de crômio, de modo que a quantidade necessária foi obtida por meio da coleta em dias sucessivos até atingir $8 \mathrm{~g}$ de MS. Antes das análises, as fezes foram moídas e homogeneizadas com gral e pistilo. Para a quantificação do óxido de crômio, as amostras das dietas e das fezes $(0,1 \mathrm{~g})$ foram digeridas com $3 \mathrm{~mL}$ de ácido nítrico e $2 \mathrm{~mL}$ de ácido perclórico em balões Kjeldahl a $400^{\circ} \mathrm{C}$ por 40 min até obtenção de uma coloração amarelada. Após diluição em $1 \mathrm{~L}$ de água destilada, a absorbância foi lida (550 nm) e a concentração de óxido de crômio determinada

Tabela 2 - Composição das dietas experimentais utilizadas em ensaio de digestibilidade com juvenis de jundiá (em \% da MS) Table 2 - Ingredient and chemical compositions of the experimental diets fed to jundia juveniles in the digestibility trial (\% DM)

\begin{tabular}{|c|c|c|c|c|c|c|}
\hline \multirow[t]{2}{*}{$\begin{array}{l}\text { Ingrediente (\%) } \\
\text { Ingredient (\%) }\end{array}$} & \multicolumn{6}{|c|}{$\begin{array}{l}\text { Dieta } \\
\text { Diet }\end{array}$} \\
\hline & $\begin{array}{l}\text { Basal } \\
\text { Basal }\end{array}$ & $\begin{array}{c}\text { Milho } \\
\text { Ground corn }\end{array}$ & $\begin{array}{c}\text { Quirera de arroz } \\
\text { Broken rice }\end{array}$ & $\begin{array}{l}\text { Farinha resíduo peixe }{ }^{1} \\
\text { Fish processing waste meal }\end{array}$ & $\begin{array}{l}\text { Farelo de soja } \\
\text { Soybean meal }\end{array}$ & $\begin{array}{l}\text { Glúten milho } \\
\text { Corn gluten meal }\end{array}$ \\
\hline Milho (Ground corn) & 15,00 & 40,11 & - & - & - & - \\
\hline Quirera de arroz (Broken rice) & 23,24 & - & 45,88 & - & - & - \\
\hline Farinha de resíduo de peixe & 21,00 & - & - & 44,31 & - & - \\
\hline \multicolumn{7}{|l|}{ Fish processing waste meal } \\
\hline Farelo de soja (Soybean meal) & 18,53 & - & - & - & 42,58 & - \\
\hline Glúten de milho (Corn gluten meal) & 15,43 & - & - & - & - & 40,41 \\
\hline Farelo de trigo (Wheat bran) & 2,00 & 1,40 & 1,40 & 1,40 & 1,40 & 1,40 \\
\hline Óleo de soja (Soybean oil) & 1,75 & 1,22 & 1,22 & 1,22 & 1,22 & 1,22 \\
\hline Óleo de peixe (Fish oil) & 1,75 & 1,22 & 1,22 & 1,22 & 1,22 & 1,22 \\
\hline Mistura mineral/vitam. ${ }^{2}$ (Min./vit. mix) & 0,80 & 0,80 & 0,80 & 0,80 & 0,80 & 0,80 \\
\hline Óxido de crômio $^{3}$ (Chromium oxide) & 0,50 & 0,50 & 0,50 & 0,50 & 0,50 & 0,50 \\
\hline \multicolumn{7}{|l|}{$\begin{array}{l}\text { Composição centesimal (\%) } \\
\text { Chemical composition (\%) }\end{array}$} \\
\hline $\mathrm{MS}(D M)$ & 94,23 & 95,01 & 92,49 & 95,38 & 93,84 & 94,17 \\
\hline $\mathrm{PB}(C P)$ & 35,78 & 27,54 & 28,55 & 42,78 & 39,91 & 48,93 \\
\hline $\mathrm{EE}$ & 7,25 & 7,02 & 6,53 & 8,03 & 5,45 & 8,87 \\
\hline CIN (Ash) & 7,80 & 7,17 & 6,17 & 12,85 & 7,44 & 6,00 \\
\hline $\mathrm{FB}^{4}(C F)$ & 6,56 & 7,35 & 8,08 & 6,07 & 9,41 & 7,61 \\
\hline $\mathrm{EB}(G E)(\mathrm{kcal} / \mathrm{kg})$ & 4.391 & 4.374 & 4.282 & 4.429 & 4.451 & 4.741 \\
\hline Óxido de crômio (Chromium oxide) & 0,48 & 0,55 & 0,50 & 0,53 & 0,54 & 0,55 \\
\hline
\end{tabular}


por meio da comparação com dosagem de uma curva padrão.

Os coeficientes de digestibilidade aparente dos nutrientes e das dietas foram determinados para os seguintes ingredientes: milho, quirera de arroz, farinha de resíduo de peixe, farelo de soja e glúten de milho por meio da seguinte fórmula, de acordo com Cho \& Slinger (1979):

$$
C D A_{(n)}=100-\left[100\left(\frac{\% \mathrm{Cr}_{2} \mathrm{O}_{3} d}{\% \mathrm{Cr}_{2} \mathrm{O}_{3} f} X \frac{\% N f}{\% N d}\right)\right]
$$

em que: $C D A_{(n)}=$ coeficiente de digestibilidade do nutriente; $\mathrm{Cr}_{2} \mathrm{O}_{3} \mathrm{~d}=\%$ de óxido de crômio na dieta; $\mathrm{Cr}_{2} \mathrm{O}_{3}$ $f=\%$ de óxido de crômio nas fezes; $N f=$ nutriente nas fezes; $N d=$ nutriente na dieta

A determinação dos coeficientes de digestibilidade aparente dos ingredientes testados foi realizada utilizando-se a seguinte relação (Cho et al., 1985):

$$
C D A_{(i)}=100 / i\left(C D A_{(d t)}-b / 100 x C D A_{(d b)}\right)
$$

em que: $C D A_{(i)}=$ coeficiente de digestibilidade aparente do ingrediente; $i=$ porcentagem do ingrediente-teste; $C D A_{(d t)}=$ coeficiente de digestibilidade aparente da dietateste; $b=$ porcentagem da dieta basal; $C D A_{(d b)}=$ coeficiente de digestibilidade aparente da dieta basal.

Os valores de energia digestível (ED) e proteína digestível (PD) foram obtidos por meio das fórmulas:

$$
E D=C D A_{(i)} x E B / 100 \text { e } P D=C D A_{(i)} x P B / 100
$$

A temperatura $\left(30,7 \pm 1^{\circ} \mathrm{C}\right)$ e a concentração de oxigênio dissolvido $(6,2 \pm 0,4 \mathrm{mg} / \mathrm{L})$ dos tanques foram medidas diariamente com auxílio de um oxímetro, enquanto as concentrações de amônia $(<0,25 \mathrm{mg} / \mathrm{L})$ e nitrito $(<0,25 \mathrm{mg} / \mathrm{L})$ e o $\mathrm{pH}(7,0 \pm 0,1)$ foram medidos semanalmente utilizando-se kits comerciais. Os parâmetros de qualidade da água estiveram dentro do limite de conforto para o jundiá (Baldissertto \& Silva, 2004).

A digestibilidade dos cinco ingredientes foi determinada em triplicata, realizadas no tempo, em delineamento em blocos ao acaso. Os coeficientes de digestibilidade aparente, em porcentagem, foram transformados a arco-seno e submetidos à análise de variância e à posterior comparação das médias pelo teste Duncan, a 5\% de significância, por meio do programa estatístico Jandel SigmaStat $2.0^{\circledR}$.

\section{Resultados e Discussão}

O tempo médio de coleta de fezes ( 25 dias) variou dependendo do ingrediente: 17, 21,21, 28, 30 e 33 dias para a farinha de resíduo de peixe, dieta basal, quirera de arroz, glúten de milho, farelo de soja e milho, respectivamente.

Conforme demonstrado na Tabela 3 , entre os ingredientes testados, a maior digestibilidade da PB (90,2\%) foi obtida no
Tabela 3 - Coeficientes de digestibilidade aparente $( \pm$ desviopadrão) das dietas para juvenis de jundiá

Table 3 - Apparent digestibility coefficients ( \pm standard deviation) of the experimental diets fed to jundia juveniles

\begin{tabular}{lccc}
\hline $\begin{array}{l}\text { Dieta } \\
\text { Diet }\end{array}$ & \multicolumn{2}{c}{$\begin{array}{c}\text { Coeficiente de digestibilidade aparente (\%) } \\
\text { Apparent digestibility coefficient }\end{array}$} \\
\cline { 2 - 4 } & \multicolumn{1}{c}{ MS } & PB & EB \\
& CP & $G E$ \\
\hline $\begin{array}{l}\text { Basal } \\
\text { Basal }\end{array}$ & $75,2 \pm 1,2$ & $88,1 \pm 1,7$ & $78,5 \pm 1,4$ \\
$\begin{array}{l}\text { Milho } \\
\text { Ground corn }\end{array}$ & $69,9 \pm 5,5$ & $83,6 \pm 3,9$ & $72,7 \pm 5,5$ \\
$\begin{array}{l}\text { Quirera de arroz } \\
\text { Broken rice }\end{array}$ & $70,9 \pm 2,4$ & $85,9 \pm 2,1$ & $74,4 \pm 1,8$ \\
$\begin{array}{l}\text { Farelo de soja } \\
\text { Soybean meal }\end{array}$ & $74,6 \pm 2,7$ & $88,3 \pm 3,0$ & $77,9 \pm 2,8$ \\
$\begin{array}{l}\text { Farinha resíduo peixe } \\
\text { Fish processing waste meal } \\
\text { Glúten de milho } \\
\text { Corn gluten meal }\end{array}$ & $70,3 \pm 2,3$ & $85,0 \pm 0,6$ & $77,4 \pm 0,6$ \\
\hline
\end{tabular}

glúten de milho e a menor (83,6\%), no milho (Tabela 3). Para a digestibilidade da energia, a mesma tendência foi observada: a dieta com glúten de milho foi a mais digestível $(81,3 \%)$ e a contendo milho a menos digestível $(72,7 \%)$. Os coeficientes de digestibilidade aparente das dietas quanto à MS variaram de 69,9\% (milho) a 77,3\% (glúten de milho). Os valores médios dos coeficientes de digestibilidade aparente da MS, PB e EB dos ingredientes testados encontram-se na Tabela 4.

Quanto à digestibilidade da MS, o glúten de milho foi o ingrediente mais digestível (82,2\%), seguido do farelo de soja, que apresentou valor intermediário $(73,3 \%)$, do milho $(57,2 \%)$, da quirera de arroz $(60,5 \%)$ e da farinha de resíduo de peixe $(58,6 \%)$. O glúten de milho destacou-se ainda quanto à digestibilidade da proteína $(95,0 \%$, maior valor), enquanto o farelo de soja $(88,6 \%)$, a quirera de arroz $(80,7 \%)$ e a farinha de resíduo de peixe $(77,7 \%)$ apresentaram valores intermediários e o milho, o menor valor $(73,0 \%)$. Considerando-se a digestibilidade energética, o glúten de milho novamente foi o ingrediente mais digestível $(88,0 \%)$, o farelo de soja e a farinha de resíduo de peixe apresentaram valores intermediários (76,5 e 74,8\%, respectivamente), enquanto o milho e a quirera de arroz foram os menos digestíveis, com valores de 59,1 e $64,8 \%$, respectivamente.

Todos os ingredientes testados neste estudo são freqüentemente utilizados na composição de rações para peixes. O milho é muito utilizado também na formulação de rações para animais monogástricos onívoros (suínos e aves), por sua alta digestibilidade nestes animais (Rostagno et al., 2000). Em peixes, entretanto, a digestibilidade do milho varia conforme a capacidade de digestão das diferentes 
Tabela 4 - Coeficiente de digestibilidade aparente da MS, PB e EB de alguns ingredientes e seus respectivos valores de proteína e energia digestíveis para juvenis de jundiá 1

Table 4 - Apparent digestibility coefficients of DM, CP, and GE and values of digestible protein and energy of some feed ingredients fed to jundia juveniles

\begin{tabular}{|c|c|c|c|c|c|}
\hline \multirow[t]{2}{*}{$\begin{array}{l}\text { Ingrediente } \\
\text { Ingredient }\end{array}$} & \multicolumn{3}{|c|}{$\begin{array}{l}\text { Coeficiente de digestibilidade aparente } \\
\text { Apparent digestibility coefficient }\end{array}$} & \multirow[t]{2}{*}{$\begin{array}{l}\text { Proteína digestível } \\
\text { Digestible protein }\end{array}$} & \multirow[t]{2}{*}{$\begin{array}{c}\text { Energia digestível }(\mathrm{kcal} / \mathrm{kg}) \\
\text { Digestible energy }\end{array}$} \\
\hline & $\begin{array}{l}\text { MS } \\
D M\end{array}$ & $\begin{array}{l}\text { PB } \\
C P \\
\%\end{array}$ & $\begin{array}{l}\text { EB } \\
G E\end{array}$ & & \\
\hline $\begin{array}{l}\text { Milho } \\
\text { Ground corn }\end{array}$ & $57,2 \pm 15,6^{\mathrm{b}}$ & $73,0 \pm 9,2^{\mathrm{c}}$ & $59,1 \pm 15,3^{b}$ & $7,0 \pm 0,9$ & 2.297 \\
\hline $\begin{array}{l}\text { Quirera de arroz } \\
\text { Broken rice }\end{array}$ & $60,5 \pm 6,3^{b}$ & $80,7 \pm 5,0^{\mathrm{bc}}$ & $64,8 \pm 5,0^{\mathrm{b}}$ & $9,2 \pm 0,6$ & 2.455 \\
\hline $\begin{array}{l}\text { Farelo de soja } \\
\text { Soybean meal }\end{array}$ & $73,3 \pm 6,5^{\mathrm{ab}}$ & $88,6 \pm 6,9^{\mathrm{ab}}$ & $76,5 \pm 6,2^{\mathrm{ab}}$ & $47,8 \pm 3,7$ & 3.194 \\
\hline $\begin{array}{l}\text { Farinha de resíduo de peixe }{ }^{2} \\
\text { Fish processing waste meal }\end{array}$ & $58,6 \pm 10,0^{\mathrm{b}}$ & $77,7 \pm 1,9^{b c}$ & $74,8 \pm 4,4^{\mathrm{ab}}$ & $47,1 \pm 1,2$ & 3.014 \\
\hline $\begin{array}{l}\text { Glúten de milho } \\
\text { Corn gluten meal }\end{array}$ & $82,2 \pm 3,0^{\mathrm{a}}$ & $95,0 \pm 1,1^{\mathrm{a}}$ & $88,0 \pm 2,8^{\mathrm{a}}$ & $67,4 \pm 0,8$ & 4.684 \\
\hline
\end{tabular}

1 Letras diferentes nas colunas indicam diferença estatística $(P<0,05)$.

2 Fabricada a partir de resíduo de filetagem.

1 Different letter superscripts in each column indicate significant difference $(P<0.05)$.

2 Fish processing waste.

espécies (Halver \& Hardy, 2002). Os peixes onívoros, em relação aos carnívoros, digerem melhor os ingredientes energéticos (Zavala-Camim, 1996). O jundiá, apesar de seu hábito alimentar onívoro, apresentou baixa digestibilidade da MS e EB deste ingrediente (57,2 e 59,1\%, respectivamente), porém, com valor médio para a proteína $(73,0 \%)$, quando comparado a outros peixes onívoros, como a piracanjuba, Brycon orbignyanus $(92,4 ; 94,4$ e $84,8 \%$ para PB, EB e MS, respectivamente) (Meurer, 1999), o pacu, Piaractus mesopotamicus $(84,4$ e $86,7 \%$ para PB e EB) (Abimorad \& Carneiro, 2002) e a tilápia-do-nilo, Oreochromis niloticus $(93,4 ; 76,6$ e 73,2\% para $\mathrm{PB}$, EB e MS, respectivamente) (Boscolo et al., 2002). Entretanto, os valores de digestibilidade encontrados neste estudo para o jundiá são mais próximos aos obtidos para o carnívoro pintado, Pseudoplatystoma coruscans (64,2\% para PB e 65,0\% para a EB) (Gonçalves \& Carneiro, 2003).

A quirera de arroz é outro ingrediente energético utilizado na fabricação de rações para peixes, além de outros subprodutos deste grão, como o farelo e a varredura. A composição centesimal desse ingrediente foi próxima à do milho, porém com maior concentração de $\mathrm{PB}(9,6 \%$ no milho e $11,4 \%$ na quirera de arroz, Tabela 1). Para a quirera de arroz, o jundiá apresentou valores médios de digestibilidade da MS (60,5\%) e EB $(64,8 \%)$ quando comparados aos da digestibilidade protéica, que foi alta $(80,7 \%)$. Estes valores foram superiores aos encontrados para o milho. Outros peixes onívoros apresentaram valores mais elevados de digestibilidade para subprodutos do arroz: a tilápia-do-nilo apresentou $94,9 \%$ para a proteína e $91,3 \%$ para a energia (Pezzato et al., 2002) e o pacu, 80,8\% para a proteína e $92,7 \%$ para a energia (Abimorad \& Carneiro, 2002). Esses resultados sugerem que estas espécies possuem sistema digestório mais adaptado a digerir ingredientes energéticos que o jundiá. No entanto, outra espécie onívora, o bagre-docanal, Ictalurus punctatus, que possui a morfologia do trato digestório semelhante à do jundiá, sem cecos pilóricos e com intestino curto, apresentou valores próximos aos encontrados neste estudo ( $73,0 \%$ para $\mathrm{PB}$ e $50,0 \%$ para $\mathrm{EB}$ ) (Wilson \& Poe, 1985). Alguns carnívoros, no entanto, apresentam valores ainda mais baixos de digestibilidade para subprodutos de arroz que os encontrados para o jundiá. O pintado, por exemplo, apresentou 43,2\% de digestibilidade da proteína e $47,3 \%$ da energia (Gonçalves \& Carneiro, 2003) e o "striped bass híbrido", Morone saxatilis $x$ M. chrysops, 71,4; 47,0 e 31,1\% da PB, EB e MS, respectivamente (Sullivan \& Reigh, 1995). É evidente a reduzida habilidade dos carnívoros em utilizar ingredientes energéticos como os subprodutos do arroz.

Os ingredientes protéicos são de melhor digestibilidade que os energéticos para o jundiá. A farinha de peixe é o principal ingrediente protéico utilizado na fabricação de rações para peixes, haja vista sua ótima palatabilidade e o bom balanço de aminoácidos (Tacon, 1987), todavia, é um ingrediente caro e sua oferta é sazonal (Macedo-Viegas \& Souza, 2004). Além disso, as diferentes espécies diferem quanto à habilidade em digerir esse alimento, que pode variar em qualidade por ser fabricado tanto com resíduos de filetagem como com o corpo inteiro do peixe. A farinha de peixe utilizada neste estudo, que é a mais facilmente encontrada no Brasil, foi a do tipo resíduo. Para o jundiá, os valores de digestibilidade para a farinha de peixe foram de 
$77,7 \%$ da PB, $74,8 \%$ da EB e $58,6 \%$ da MS. A baixa digestibilidade da MS em relação aos outros nutrientes pode ser explicada pela grande quantidade de cinzas $(25,2 \%)$ neste ingrediente. Outra espécie onívora que apresenta baixos valores de digestibilidade para a farinha de resíduo de peixe é a piracanjuba (63,1\% da PB, 38,5\% do EE e $22,3 \%$ da MS) (Meurer, 1999). Em tilápias-do-nilo, no entanto, para este mesmo ingrediente, foram obtidos valores de digestibilidade próximos ao encontrado com o jundiá (78,6\% da PB, 72,2\% da EB e 57,5\% da MS) (Pezzato et al., 2002). O pintado, por sua vez, aproveitou melhor a farinha de resíduo de peixe ( $84,1 \%$ da proteína e $72,8 \%$ da energia) (Gonçalves $\&$ Carneiro, 2003). Quando a farinha de peixe é fabricada com o corpo inteiro, no entanto, os valores de digestibilidade são altos (acima de $80 \%$ ) tanto para os peixes onívoros quanto para os carnívoros (Wilson \& Poe, 1985; Sullivan \& Reigh, 1995; Degani et al., 1997; Allan et al., 2000).

Com a redução dos estoques pesqueiros e considerando o alto preço, muitos estudos têm sido realizados na tentativa de substituir a farinha de peixe por outros ingredientes protéicos, principalmente os de origem vegetal (Gomes et al., 1995; Booth et al., 2001). O farelo de soja tem sido apontado como a principal alternativa de substituição por apresentar alta porcentagem de PB e conter a maioria dos aminoácidos essenciais para os peixes (NRC, 1993). O jundiá apresentou boa digestibilidade do farelo de soja (73,3\% da PB, 88,6\% da EB e 76,5\% da MS) em relação aos ingredientes energéticos, embora seja um ingrediente com razoável quantidade de fibra $(8,6 \%)$. Muitos estudos demonstram a boa digestibilidade (acima de 70\%) deste ingrediente tanto para peixes onívoros - bagre-docanal ( $97,0 \%$ da PB e $72,0 \%$ da EB) (Wilson \& Poe, 1985), perca prateada, Bidyanus bidyanus (78,0\% da EB e 75,4\% da MS) (Allan et al., 2000) e tilápia-do-nilo (91,6 da PB, 73,2\% da EB e 71,0\% da MS) (Pezzato et al., 2002) - como para os carnívoros - "haddock", Melanogrammus aeglefinus ( $92,2 \%$ da PB, $92,1 \%$ da EB, $89,0 \%$ da MS) (Tibbetts et al., 2004), e "black bass", Micropterus salmoides $(94,3 \%$ da PB, 75,4\% da EB e 70,4\% da MS) (Portz \& Cyrino, 2004).

O glúten de milho, um subproduto da fabricação do amido de milho, é um ingrediente de origem vegetal bastante estudado como alternativa de fonte protéica (Tacon, 1987) e, entre os ingredientes testados, foi o que apresentou os melhores índices de digestibilidade para o jundiá (95,0\% da PB, $88,0 \%$ da EBe $82,2 \%$ da MS). Em outros estudos testando a digestibilidade deste ingrediente em peixes onívoros e carnívoros, também foram observados resultados superiores a 70\% de digestibilidade: $96,0 \%$ da PB, $71,2 \%$ da EB e $92,0 \%$ da MS em tilápias-do-nilo (Pezzato et al., 2002); 93,6\% da PB, 76,5\% da EB e 75,3\% da MS em "black bass" (Portz \& Cyrino, 2004); 92,3\% da PB, 80,7\% da EB e 72,6\% da MS em "haddock" (Tibbetts et al., 2004); e $94,4 \%$ da PB, $94,2 \%$ da EB e $84,6 \%$ da MS em "cobia", Rachycentron canadum (Zhou et al., 2004). Esses excelentes valores de digestibilidade tanto para peixes onívoros como carnívoros, podem ser explicados pela elevada porcentagem de proteína $(60 \%)$ e pela baixa quantidade de fibra $(2,5 \%)$ deste ingrediente.

\section{Conclusões}

O jundiá digere melhor os ingredientes ricos em proteína bruta (glúten de milho, farelo de soja e farinha de resíduo de peixe) que os energéticos (milho e quirera de arroz), de modo similar ao que acontece em alguns peixes onívoros e principalmente nos carnívoros. Entretanto, a digestibilidade dos ingredientes energéticos para o jundiá, comparada à dos peixes carnívoros, é levemente superior. Considerando-se a utilização dos nutrientes dos ingredientes testados, pode-se afirmar que o jundiá é um peixe onívoro com tendência à carnivoria.

\section{Agradecimento}

À Nicoluzzi Rações LTDA (Penha, SC), pela doação dos ingredientes utilizados no presente estudo; ao CNPq, pelo financiamento (474338/04-5); è̀ CAPES, pela bolsa de estudos concedida ao primeiro autor.

\section{Literatura Citada}

ABIMORAD, E.G.; CARNEIRO, D.J. Determinação dos coeficientes de digestibilidade da proteína e da energia dos alimentos para o pacu, Piaractus mesopotamicus. In: SIMPÓSIO BRASILEIRO DE AQUiCUlturA, 12., 2002, Goiânia. Anais... Goiânia: CAUNESP/ESALQ, 2002. p.96.

ALLAN, G.L.; PARKINSON, S.; BOOTH, M.A. et al. Replacement of fish meal in diets for Australian silver perch, Bidyanus bidyanus: I Digestibility of alternative ingredients. Aquaculture, v.186, n.3-4, p.293-310, 2000.

ASSOCIATION OF OFFICIAL ANALITICAL CHEMISTS - AOAC Official methods of analysis. 16.ed. Washington, D.C. 1999. $1141 \mathrm{p}$.

AUSTRENG, E. Digestibility determinations in fish using chromic oxide marker and analysis of contents from different segments of the gastro-intestinal tract. Aquaculture, v.13, n.3, p.265-272, 1978

BALDISSEROTTO, B.; SILVA, L.V.F. Qualidade da água. In: BALDisserotTo, B.; RADUNZ NETO, J. (Eds.) Criação de jundiá. Santa Maria: Universidade Federal de Santa Maria, 2004. p.73-92.

BOOTH, M.A.; ALLAN, G.L.; FRANCES, J. et al. Replacement of fish meal in diets for Australian silver perch, Bidyanus bidyanus. IV: Effects of dehuling and protein concentration on digestibility of grain legumes. Aquaculture, v.196, n.1-2, p.67-85, 2001

BOSCOLO, W.R.; HAYASHI, C.; MEURER, F. Digestibilidade aparente da energia e nutrientes de alimentos convencionais e 
alternativos para a tilápia do Nilo (Oreochromis niloticus). Revista Brasileira de Zootecnia, v.31, n.2, p.539-545, 2002. BREMER NETO, H.; GRANER, C.A.F.; PEZZATO, L.E. et al. Diminuição do teor de óxido de cromio (III) usado como marcador externo. Revista Brasileira de Zootecnia, v.32, n.2, p.249-255, 2003.

CARNEIRO, P.C.F.; BENDHACK, F.; MIKOS, J.D. et al. Jundiá: um grande peixe para a região sul. Panorama da Aqüicultura, v.12, n.69, p.41-46, 2002.

CHO, C.Y.; SLINGER, S.J. Apparent digestibility measurement in feedstuffs for rainbow trout. In: FINFISH NUTRITION AND FISHFEED TECHNOLOGY, 1979, Berlim. Anais... Berlim: 1979. v.2, p.239-247.

CHO, C.Y.; COWEY, C.B.; WATANABE, T. Finfish nutrition on Asia: method-logical approaches to research and development. Ottawa: International Development Research Center, 1985. 154p.

ChOUBert, G.; DE LA NOUE, J.; LUQUeT, P. Continuous quantitative automatic collector for fish feces. Progressive Fish Culturist, v.41, p.64-67, 1979.

COLDEBELlA, I.J.; RADUNZ NETO, J. Farelo de soja na alimentação de alevinos de jundiá, Rhamdia quelen. Ciência Rural, v.32, n.3, p.499-503, 2002.

DEGANI, G.; YEHUDA, Y.; VIOLA, S. The digestibility of nutrients sources for common carp, Cyprinus carpio. Aquaculture Research, v.28, n.8, p.575-580, 1997.

DE SILVA, S.S.; ANDERSON, T.A. Fish nutrition in aquaculture. London: Chapman \& Hall, 1998, 319p.

FRACALOSSI, D.M.; MEYER, G.; WEINGARTNER, M. et al. Criação do jundiá, Rhamdia quelen, e dourado, Salminus brasiliensis em viveiros de terra na região Sul do Brasil. Acta Scientiarum, v.26, n.3, p.345-352, 2004.

GOMES, E.F.; REMA, P.; KAUSHIK, S.J. Replacement of fish meal by plant proteins in the diet of rainbow trout (Oncorhynchus mykiss): digestibility and growth performance. Aquaculture, v.130, n.2-3, p.177-186, 1995.

GOMES, L.C.; GOLOMBIESKI, J.I.; GOMES, A.R.C. et al. Biologia do jundiá, Rhamdia quelen (Teleostei, Pimelodidae). Ciência Rural, v.30, p.179-185, 2000.

GONÇALVES, E.G.; CARNEIRO, D.J. Coeficiente de digestibilidade aparente da proteína e energia de alguns ingredientes utilizados em dietas para o pintado (Pseudoplatystoma coruscans). Revista Brasileira de Zootecnia, v.32, n.4, p.779-786, 2003.

GUEDES, D.S. Contribuição ao estudo da sistemática e alimentação de jundiás (Rhamdia spp) na região central do Rio Grande do Sul (Pices, Pimelodidae). Santa Maria: Universidade Federal de Santa Maria, 1980.100p. Dissertação (Mestrado em Zootecnia) - Universidade Federal de Santa Maria, 1980.

HALVER, J.E.; HARDY, R.W. Nutrient flow and retention In: HALVER, J.E.; HARDY, R.W. (Eds.) Fish nutrition. 3.ed. San Diego: Elsevier Science, 2002. p.756-769.

MACEDO-VIEGAS, E.M.; SOUZA, M.L.R. Pré-processamento e conservação do pescado produzido em piscicultura. In: CYRINO, J.E.P.; URBINATI, E.C.; FRACALOSSI, D.M. et al. (Eds.) Tópicos especiais em piscicultura de água doce tropical intensiva. São Paulo: TecArt, 2004. p.405-480.

MELO, J.F.B.; RADUNZ NETO, J.; SILVA, J.H.S. et al. Desenvolvimento e composição corporal de alevinos de jundiá (Rhamdia quelen) alimentados com dietas contendo diferentes fontes de lipídios. Ciência Rural, v.32, n.2, p.323-327, 2002.

MEURER, S. Digestibilidade aparente da matéria seca, proteína e energia brutas de alguns ingredientes para juvenis de piracanjuba, Brycon orbignyanus. Florianópolis: Universidade Federal de Santa Catarina, 1999. 81p. Dissertação (Mestrado em Aqüicultura) - Universidade Federal de Santa Catarina, 1999.

MEURER, S.; ZANIBONI FILHO, E. Hábito alimentar do jundiá, Rhamdia quelen (Pisces, Siluriformes, Pimelodidae), na região do alto rio Uruguai. In: ENCONTRO BRASILEIRO DE ICTIOlOGiA, 12., 1997, São Paulo. Anais... São Paulo: Sociedade Brasileira de Ictiologia, 1997. p.29.

MEYER, G.; FRACALOSSI, D.M. Protein requirement of jundiá fingerlings, Rhamdia quelen, at two dietary energy concentrations. Aquaculture, v.240, n.4, p.331-343, 2004.

NATIONAL RESEARCH COUNCIL - NRC. Nutrient requirements of warmwater, fishes and shellfishes: nutrients requirements of domestic animals. Washington, D.C.: 1993. 114p.

PEZZATO, L.E.; MIRANDA, E.C.; BARROS, M.M. et al. Digestibilidade aparente de ingredientes para a tilápia do Nilo (Oreochromis niloticus). Revista Brasileira de Zootecnia, v.31, n.4, p.1595-1604, 2002.

PORTZ, L.; CYRINO, J.E. Digestibility of nutrients and amino acids of different protein sources in practical diets by largemouth bass, Micropterus salmoides. Aquaculture Research, v.35, n.4, p.312-320, 2004.

ROSTAGNO, H.S.; ALBINO, L.F.T.; DONZELE, J.L. et al. Tabelas brasileiras para aves e suínos: composição de alimentos e exigências nutricionais. Viçosa, MG: Universidade Federal de Viçosa, 2000. 141p.

SILFVERGRIP, A.M.C. A systematic revision of the neotropical catfish genus Rhamdia (Teleostei, Pimelodidae). Stockholm: Stockholm University and Department of Vertebrate Zoology, Swedish Museum of Natural History, 1996. 156p. (PhD Thesis) - Stockholm University and Department of Vertebrate Zoology, Swedish Museum of Natural History, 1996.

SULLIVAN, J.A.; REIGH, R.C. Apparent digestibility of selected feedstuffs in diets for hybrid striped bass (Morone saxatilis $x$ Morone chrysops). Aquaculture, v.138, n.1-4, p.313-322, 1995.

TACON, A.G.J. Nutrition and feeding of farmed fish and shrimp: a training manual. Redmond: Argent Laboratories Press, 1987. $454 \mathrm{p}$.

TibBetTs, S.M.; SANTOSH, P.H.; Milley, J.E. Apparent digestibility of common feed ingredients by juvenile haddock, Melanogrammus aeglefinus. Aquaculture Research, v.35, n.7, p.643-651, 2004.

WILSON, R.P.; POE, W.E. Apparent digestibility protein and energy coefficients of common feed ingredients for channel catfish. Progressive Fish Culturist, v.47, n.3, p.154-158, 1985

ZAVALA-CAMIM, L.A. Introdução aos estudos sobre alimentação natural em peixes. Maringá: Nupelia, 1996, 129p.

ZHOU, Q.C.; TAN, B.P.; MAI, K.S. et al. Apparent digestibility of selected feed ingredients for juvenile cobia, Rachycention canadum. Aquaculture, v.241, n.1-4, p.441-451, 2004.
Recebido: 21/07/05 Aprovado: 03/03/06 